\title{
Role of Tissue Dissociation Enzymes on Human Islet Yield Intended for Clinical Islet Cell Transplantation
}

\author{
Gopalakrishnan Loganathan ${ }^{1}$, Venugopal Subhashree ${ }^{2}$ and Appakalai N Balamurugan ${ }^{1 *}$ \\ ${ }^{1}$ Clinical Islet Cell Laboratory, Cardiovascular Innovation Institute, Department of Surgery, University of Louisville, Kentucky, USA \\ ${ }^{2}$ School of Biosciences and Technology, VIT University, Vellore, India
}

"Corresponding author: Appakalai N Balamurugan, Ph. D Clinical Islet Cell Laboratory, Center for Cellular Transplantation, Cardiovascular Innovation Institute, Department of Surgery, University of Louisville, Louisville, KY, USA, Tel: 502-794-7070; E-mail: bala.appakalai@louisville.edu

Received date: December 28, 2016; Accepted date: December 30, 2016; Published date: December 31, 2016

Copyright: @ 2016 Loganathan G, et al. This is an open-access article distributed under the terms of the Creative Commons Attribution License, which permits unrestricted use, distribution and reproduction in any medium, provided the original author and source are credited.

Keywords: Collagenase; Chronic pancreatitis; Pancreatectomy; Autograft; Allograft; Human islets; Islet isolation; Transplantation; Insulin independence; Collagenase digestion

\section{Introduction}

Clinical islet transplantation is a well-established and a relatively safe procedure for diabetic patients, whereas autologous islet transplantation is performed as an adjunctive therapy following a total or partial pancreatectomy from patients with chronic pancreatitis. Successful clinical human allo or auto-islet transplantation requires recovery of a sufficient number of functional islets from cadaveric or chronic pancreatitis pancreata. During the last two decades, significant progress has been made in the islet isolation procedures and in the use of tissue dissociation enzymes. However, it is still challenging to recover all available islets from pancreas. In many centers, about $50 \%$ of the islet isolations do not generate a sufficient number of islets for single donor transplants. Poor islet recovery remains, a critical issue which must be addressed so to achieve widespread adoption of islet transplantation. This review will present information focusing on role of tissue dissociation enzymes and their properties during islet isolation, particularly emphasizing on the current developments within the field.

\section{Bacterial Collagenase from Clostridium histolyticum}

Historically, it has been demonstrated that utilizing a precise, collagenase containing enzyme blend for pancreatic islet isolation is a critical parameter for successful islet transplantation.

Collagenase is an endopeptidase enzyme produced from the fermentation broth of Clostridium histolyticum. By definition, collagenase has a unique specificity since it cuts the triple helical structure of native collagen. Proteases are ineffective at degrading collagen's triple helix. Collagens are the major component of the connective tissue extracellular matrix (ECM). The biological and enzymatic properties of $C$. histolyticum collagenase are well documented [1]. Collagenase is produced by two distinct genes, $c o l G$ and $c o l H$, coding for Class I (C1) and Class II (C2) collagenases having molecular weights of $116 \mathrm{kDa}$ and $114 \mathrm{kDa}$, respectively [2]. C1 and $\mathrm{C} 2$ collagenases appear to digest all forms of collagen since the triple helical structure is a key component of these molecules. The C1 and C2 enzymes work synergistically to hydrolyze these helical structures into smaller peptides [3].

Collagenase was first commercially available from Worthington Biochemical Corporation in 1959. By 1970's many other suppliers manufactured a "crude collagenase" produced from C. histolyticum, which contained many other enzymes such as collagenase, phospholipase, clostripain, elastase, aminopeptidase, galactosidase, and other proteases [4]. This crude product was widely used to isolate specific cell types from different tissue sources such as pancreas [5], liver [6], cartilage [7], heart [8], adipose [9], and bone [10].

Until the 1990's, pancreatic islet isolation was processed using the crude or enriched collagenase [11]. The major hurdles of using these products for islet isolation were lot to lot variability of enzyme activity and high endotoxin content. To overcome these issues, a purified enzyme blend from Boehringer Mannheim Biochemicals (now sold by Roche), "Liberase-HI Purified Enzyme Blend" was introduced in 1994. This enzyme was provided as one vial with a fixed enzyme dose. It contained $\mathrm{C} 1 / \mathrm{C} 2$ collagenase from $C$. histolyticum and thermolysin, a thermostable neutral protease from Bacillus thermolyticus rokko, and low endotoxin contamination. Introducing this enzyme in the market immediately improved islet yields from clinical islet isolation procedures [12]. As a result, crude enzyme usage declined for human islet isolation. However, purification of collagenase did not eliminate batch variability because many laboratories obtained inconsistent islet isolation results.

\section{Class I and Class II Collagenases}

The purified enzymes blend currently used for islet isolation comprise of class I and class II collagenases. The C1 and C2 collagenases work synergistically to degrade native collagen [13]. The ratio between $\mathrm{C} 1$ and $\mathrm{C} 2$ collagenases is important for optimal islet isolation in rat and human pancreas $[14,15]$. $\mathrm{C} 1$ is more stable and has a greater activity towards native collagen, whereas $\mathrm{C} 2$ has the ability to digest a broader range of peptide substrates when compared to C1. Among the three well-known enzyme suppliers (VitaCyte, Serva, and Roche), only the VitaCyte and Roche C1/C2 collagenase ratio is known (60:40) [16]. Our previous studies have demonstrated that different $\mathrm{C} 1 / \mathrm{C} 2$ ratios and doses of purified collagenase, when tested for human islet isolation, had no significant effect on digestion and islet yield [17].

\section{Role of Proteases in Islet Isolation}

Collagenase and proteases are required for successful islet isolation. Purified collagenase lack proteases which necessitates the addition of proteases that complement the collagenase activity, leading to successful islet recovery. Neutral protease from C. histolyticum and thermolysin have been extensively used in clinical islet isolations. In addition, BP protease ('dispase' equivalent enzyme) from Paneibacillus polymyxa has also successfully been used for human islet isolation [17]. 


\section{Collagenase Enzyme Activity Assessment}

Currently, clinical islet isolation enzyme suppliers (VitaCyte, Serva/ Nordmark, and Roche), express their enzyme (collagenase) activity in 'Wunsch units'. The Wunsch and FALGPA assays use a peptide substrate that preferentially detects collagenase activity, these peptidase assays primarily detect $\mathrm{C} 2$ activity and assess only the function of the catalytic domain. In contrast, the true functional collagenase activity is detected by using a native collagen substrate. VitaCyte's fluorescent microplate collagen degradation activity (CDA) assay measures enzyme that contain a catalytic domain and a collagen binding domain. The collagenase must first securely bind to native collagen before the catalytic domain in the same molecule can cut collagen's triple helical structure. Treatment of collagenase with chymotrypsin leads to removal of collagen binding domains and loss of nearly all the CDA activity with minimal change in the Wunsch activity. Studies at VitaCyte has shown the specific CDA activity of C1116 kDa is about 7-8 times higher than the $\mathrm{C} 1100 \mathrm{kDa}$ or $\mathrm{C} 2114 \mathrm{kDa}$ forms of collagenase [28].

\section{Clinical Islet Isolation Enzymes}

In 2007, the purified enzyme Liberase-HI, was withdrawn from the market because of safety concerns associated with the use of bovine brain-derived materials during the fermentation process. Identifying a replacement enzyme blend became imperative for successful continuation of clinical islet transplant programs across the globe [18]. During that time, the only available enzyme for clinical isolation was Serva/Nordmark collagenase NB1 [19]. The purified clinical grade collagenase and neutral protease enzymes were supplied in independent vials. Left with no alternatives, many centers took time to standardize and establish isolation protocols with these enzymes, which gave lower islet yields that led to fewer islet transplantation procedures $[18,20]$.

Eventually, Szot et al. [2009] in used the Serva/Nordmark enzyme to isolate islets and use a high percentage of these preparations for clinical allo-transplantation [21]. As part of the islet group at the University of Minnesota, we also reported that the same enzyme could be successfully utilized for autologous islet isolation from chronic pancreatitis pancreata. The results from autologous islet isolation using the Collagenase NB1 were comparable with traditional Liberase-HI in terms of islet yield and clinical outcome [22].

Purified tissue dissociation enzymes (TDEs) are critical to successful human islet isolation, but little was known about the key enzymes-class I (C1) and class II (C2) collagenase characteristics. We were the first group to demonstrate differences between the $\mathrm{C} 1$ collagenase found in purified collagenase products manufactured by three main suppliers and evaluated the impact of $\mathrm{C} 1$ differences between two suppliers on human islet yield. Our results indicated the importance of intact $\mathrm{C} 1$ collagenase, necessary for successful human islet isolation and transplantation [23].

Kin et al. [2009] improved the islet isolation outcome by nonsimultaneous administration of collagenase and protease [24]. Furthermore, Brandhorst et al. [2009] performed a detailed enzyme activity analyses for the current enzyme lots [25] and they determined the high tryptic-like activity as a key parameter for the functioning of pancreatic dissociation enzymes. In order to identify suitable enzyme combinations, we also evaluated many different enzyme products containing different levels of intact or truncated collagenases, used in combination with thermolysin or neutral protease. We incorporated biochemical analysis of the collagenase enzymes as part of our evaluation criteria and identified a new blend containing intact class I $(\mathrm{C} 1) /$ class II (C2) collagenase and neutral protease, both from $C$. histolyticum, and called it the new enzyme mixture (NEM). Isolations with our NEM were a lot more effective than any other enzyme combination, recovering consistently high yields of quality islets from human pancreata [23]. Additionally, clinical autologous and allotransplantations with islets isolated from the NEM achieved greater success [23].

During this course of enzyme standardization, Roche introduced Liberase MTF, a new preparation of, purified collagenase and purified thermolysin. HPLC analysis confirmed that their product had intact $\mathrm{C} 1$ collagenase. This enzyme was successfully utilized for clinical islet isolations [26,27].

Over the years, the trend has been to utilize collagenase with a protease as an enzyme combination to improve islet yield. In the last decade (2007-2016) particularly, three different enzyme combinations (from Serva, Vitacyte, and Roche) have been implemented for clinical preparations. Though all these enzymes were successfully utilized for processing clinical isolations, only an average of $50 \%$ have yielded sufficient islet numbers for transplantation [20].

Despite successful utilization of enzyme combinations from different providers, one of the persistent challenges which requires immediate attention is the variability in islet yield. Several factors contribute to this variability. Total islet number within whole pancreas has not yet been determined. In this context, further optimization of the enzyme type or dose and better understanding of the extracellular matrix of human pancreas, is required for improving islet yield.

\section{Conclusion}

Collagen is the most abundant protein within human pancreas. Human donor's differ tissue characteristics due to genetic and environmental factors. Critical analysis of how collagenase and protease enzymes may act on known and novel tissue substrates, present within the ECM, for better tissue dissociation is subject to further investigation. In this context, we recently introduced a recombinant collagenase enzyme which demonstrated better outcomes when compared to previously used enzyme combinations [17]. Further evaluation is necessary to optimize enzyme doses and combinations to reach a degree of consensus. An enzyme blend which core islet facilities across the world can utilize as a consensus mixture would be ideal, this becoming one of the ultimate goals within clinical islet research requiring collaboration between islet centers and core facilities, enzyme companies and clinicians.

\section{Acknowledgement}

The authors thank the Jewish Heritage Fund for Excellence for providing generous support to our program. The authors sincerely thank Kentucky Organ Donor Affiliates (KODA) for the supply of human pancreases. Special thanks to Siddharth Narayanan and Robert C. McCarthy for their assistance.

\section{References}

1. Bond MD, Van Wart HE (1984) Characterization of the individual collagenases from Clostridium histolyticum. Biochemistry 23: 3085-3091. 
Citation: Loganathan G, Subhashree V, Balamurugan AN (2016) Role of Tissue Dissociation Enzymes on Human Islet Yield Intended for Clinical Islet Cell Transplantation . J Transplant Technol Res 6: e136. doi:10.4172/2161-0991.1000e136

Page 3 of 3

2. Matsushita O, Jung CM, Katayama S, Minami J, Takahashi Y, et al. (1999) Gene duplication and multiplicity of collagenases in Clostridium histolyticum. J Bacteriol 181: 923-933.

3. French MF, Mookhtiar KA, Van Wart HE (1987) Limited proteolysis of type I collagen at hyperreactive sites by class I and II Clostridium histolyticum collagenases: complementary digestion patterns. Biochemistry 26: 681-687.

4. Kono T (1968) Purification and partial characterization of collagenolytic enzymes from Clostridium histolyticum. Biochemistry 7: 1106-1114.

5. Moskalewski S (1965) Isolation and culture of the islets of langerhans of the guinea pig. Gen Comp Endocrinol 5: 342-353.

6. Howard RB, Christensen AK, Gibbs FA, Pesch LA (1967) The enzymatic preparation of isolated intact parenchymal cells from rat liver. J Cell Biol 35: 675-684

7. Manning WK, Bonner WM Jr (1967) Isolation and culture of chondrocytes from human adult articular cartilage. Arthritis Rheum 10: 235-239.

8. Moustafa E, Skomedal T, Osnes JB, Oye I (1976) Cyclic AMP formation and morphology of myocardial cells isolated from adult heart: effect of $\mathrm{Ca} 2+$ and Mg2+. Biochimica et biophysica acta 421: 411-415

9. Rodbell M (1964) Localization of lipoprotein lipase in fat cells of rat adipose tissue. J Biol Chem 239: 753-755.

10. Fedarko NS, Termine JD, Young MF, Robey PG (1990) Temporal regulation of hyaluronan and proteoglycan metabolism by human bone cells in vitro. J Biol Chem 265: 12200-12209.

11. Ricordi C, Carroll P, Tzakis A, Zeng Y, Rilo HL, et al. (1992) Outcome of human islet isolation and allotransplantation in 20 consecutive cases. Diab Nutr \& Metab 1: 193-198.

12. Linetsky E, Bottino R, Lehmann R, Alejandro R, Inverardi L, et al. (1997) Improved human islet isolation using a new enzyme blend liberase. Diabetes 46: 1120-1123.

13. Wolters GH, Vos-Scheperkeuter GH, Lin HC, van Schilfgaarde R (1995) Different roles of class I and class II Clostridium histolyticum collagenase in rat pancreatic islet isolation. Diabetes 44: 227-233.

14. Brandhorst H, Raemsch-Guenther N, Raemsch C, Friedrich O, Huettler S, et al. (2008) The ratio between collagenase class I and class II influences the efficient islet release from the rat pancreas. Transplantation 85: 456-461.

15. Kin T, Zhai X, O Gorman D, Shapiro AM (2008) Detrimental effect of excessive collagenase class II on human islet isolation outcome. Transpl Int 21: 1059-1065.

16. Balamurugan AN, Breite AG, Anazawa T, Loganathan G, Wilhelm JJ, et al. (2010) Successful human islet isolation and transplantation indicating the importance of class 1 collagenase and collagen degradation activity assay. Transplantation 89: 954-961.

17. Balamurugan AN, Michael GL, Breite AG, Loganathan G, Wilhelm JJ, et al. (2016) Identifying effective enzyme activity targets for recombinant class I and class II collagenase for successful human islet isolation. Transplantation Direct 2: e54.

18. Alejandro R, Barton FB, Hering BJ, Wease S (2008) Collaborative islet transplant registry I 2008 update from the collaborative islet transplant registry. Transplantation $86:$ 1783-1788.

19. Brandhorst H, Friberg A, Nilsson B, Andersson HH, Felldin M, et al. (2010) Large-scale comparison of Liberase HI and collagenase NB1 utilized for human islet isolation. Cell Transplant 19: 3-8.

20. Balamurugan AN, Naziruddin B, Lockridge A, Tiwari M, Loganathan G, et al. (2014) Islet product characteristics and factors related to successful human islet transplantation from the Collaborative Islet Transplant Registry (CITR) 1999-2010. Am J Transplant 14: 2595-2606.

21. Szot GL, Lee MR, Tavakol MM, Lang J, Dekovic F, et al. (2009) Successful clinical islet isolation using a GMP-manufactured collagenase and neutral protease. Transplantation 88: 753-756.

22. Anazawa T, Balamurugan AN, Bellin M, Zhang HJ, Matsumoto S, et al. (2009) Human islet isolation for autologous transplantation: comparison of yield and function using SERVA/Nordmark versus Roche enzymes. Am J Transplant 9: 2383-2391.

23. Balamurugan AN, Loganathan G, Bellin MD, Wilhelm JJ, Harmon J, et al. (2012) A new enzyme mixture to increase the yield and transplant rate of autologous and allogeneic human islet products. Transplantation 93: 693-702.

24. Kin T, O Gorman D, Zhai X, Pawlick R, Imes S, et al. (2009) Nonsimultaneous administration of pancreas dissociation enzymes during islet isolation. Transplantation 87: 1700-1705.

25. Brandhorst H, Friberg A, Andersson HH, Felldin M, Foss A, et al. (2009) The importance of tryptic-like activity in purified enzyme blends for efficient islet isolation. Transplantation 87: 370-375.

26. Caballero-Corbalan J, Friberg AS, Brandhorst H, Nilsson B, Andersson $\mathrm{HH}$, et al. (2009) Vitacyte collagenase HA: a novel enzyme blend for efficient human islet isolation. Transplantation 88: 1400-1402.

27. Qi M, Valiente L, McFadden B, Omori K, Bilbao S, et al. (2015) The choice of enzyme for human pancreas digestion is a critical factor for increasing the success of islet isolation. Transplant Direct 4: 1-9.

28. McCarthy RC, Breite AG, Green ML, Dwulet FE (2011) Tissue dissociation enzymes for isolating human islets for transplantation factors to consider in setting enzyme acceptance criteria. Transplantation 91: 137-145. 